This item was submitted to Loughborough's Research Repository by the author.

Items in Figshare are protected by copyright, with all rights reserved, unless otherwise indicated.

\title{
Reduced-scale ultrasonic modelling of Rayleigh wave transmission over seismic barriers formed by periodic arrays of vertical holes
}

\section{PLEASE CITE THE PUBLISHED VERSION}

https://doi.org/10.3397/1/37664

\section{PUBLISHER}

(C) Institute of Noise Control Engineering (INCE-USA)

\section{VERSION}

AM (Accepted Manuscript)

\section{PUBLISHER STATEMENT}

This work is made available according to the conditions of the Creative Commons Attribution-NonCommercialNoDerivatives 4.0 International (CC BY-NC-ND 4.0) licence. Full details of this licence are available at: https://creativecommons.org/licenses/by-nc-nd/4.0/

\section{LICENCE}

CC BY-NC-ND 4.0

\section{REPOSITORY RECORD}

Ouahabi, Abdelhalim Azbaid El, and Victor V. Krylov. 2018. "Reduced-scale Ultrasonic Modelling of Rayleigh Wave Transmission over Seismic Barriers Formed by Periodic Arrays of Vertical Holes”. figshare. https://hdl.handle.net/2134/32220. 


\section{Reduced-scale ultrasonic modelling of Rayleigh wave}

\section{transmission over seismic barriers formed by periodic}

\section{arrays of vertical holes}

Abdelhalim Azbaid El Ouahabi ${ }^{\text {a) }}$ and Victor V. Krylov ${ }^{\text {a) }}$

Seismic barriers are used widely to protect buildings from traffic-induced ground vibrations, mainly from propagating Rayleigh surface waves. Experimental investigations of real size seismic barriers at frequencies typical for traffic-induced ground vibrations, i.e. at $\mathbf{1 0 - 1 0 0 ~} \mathrm{Hz}$, are costly and time consuming. In the present work, an alternative and much less expensive approach is proposed - a reduced-scale experimental modelling using ultrasonic Rayleigh wave propagation over very small-scale replicas of real seismic barriers. Experimental investigations of propagation of Rayleigh wave pulses with the central frequency of $1 \mathrm{MHz}$ have been carried out for seismic barriers formed by periodic arrays of vertical holes in Aluminium samples. Measurements of transmission and reflection coefficients of Rayleigh waves for different types of arrays and for different incident angles have been carried out

\footnotetext{
a) Department of Aeronautical and Automotive Engineering, Loughborough University, Loughborough, Leicestershire, LE11 3TU, UK; email: V.V.Krylov@lboro.ac.uk (V.V. Krylov)
} 


\section{and compared with the earlier published results obtained for real seismic barriers.}

Primary subject classification: 43.2.4; Secondary subject classification: 13.4.3

\section{INTRODUCTION}

Ground vibrations generated by rail and road traffic can disturb residents of nearby buildings and can even cause structural damage to properties in especially severe cases. A simple and efficient way to reduce ground vibrations from railways or road traffic is to influence the propagation path from source to receiver by introducing seismic barriers. The advantage of interventions on the propagation path is that no modifications of the track or road are required. Several types of seismic barriers have been proposed in the past to protect buildings from traffic-induced ground vibrations, mainly from propagating Rayleigh surface waves. Among such barriers are trenches (both open and in-filled) ${ }^{1-8}$, large concrete blocks embedded in the ground ${ }^{9-11}$, rows of vertical piles ${ }^{12-15}$, periodic arrays of vertical holes ${ }^{16}$, heavy masses placed on the ground surface ${ }^{17,18}$, etc.

Theoretical predictions of Rayleigh wave propagation through such barriers are extremely difficult. Analytical solutions are possible only for a limited number of cases, for example for very shallow trenches ${ }^{19}$. In the majority of practical situations though, in particular for deep trenches, the only methods of theoretical prediction are numerical approaches, which require much of computation time. For that reason, in order to obtain a reliable prediction of the behaviour of seismic barriers in specific locations, a typical practical solution is to use direct experimental measurements on real size seismic barriers at frequencies typical for traffic- 
induced ground vibrations, i.e. at $10-100 \mathrm{~Hz}^{11,20,21}$. Unfortunately, such direct measurements are costly and time consuming.

In the present paper, an alternative and much less expensive approach to a full-scale experimental testing is proposed. This is reduced-scale experimental modelling using ultrasonic Rayleigh wave propagation over very small-scale replicas of real seismic barriers. The principle of reduced-scale ultrasonic modelling is based on the fact that scattering of Rayleigh waves on topographic irregularities depends on the values of non-dimensional parameters, such as $h / \lambda_{R}$, where $h$ is one of the dimensions of the irregularity, for example depth, and $\lambda_{R}=v_{R} / f$ is the Rayleigh wavelength, where $v_{R}$ is Rayleigh wave velocity in the solid medium, and $f$ is frequency. If to increase frequency $f$ of the incident wave from sound to ultrasound, which will reduce $\lambda_{R}$ from a few meters to a few millimetres, then the same values of $h / \lambda_{R}$, and thus the same behaviour of the seismic barrier, can be achieved for the values of $h$ in the range of few millimetres. This constitutes a major achievement of ultrasonic modelling, namely that propagation of Rayleigh waves over real seismic barriers can be modelled in a much smaller scale by propagation of ultrasonic Rayleigh waves over very small replicas of seismic barriers made on the surfaces of experimental solid samples. Note that very similar problems are considered in ultrasonic non-destructive testing with regard to identification of parameters of cracks and other defects (see e.g. Refs. 22-25).

It should be noted that, whereas material damping is important for description of propagation of ground vibrations over long distances (hundreds of meters), it is insignificant if the problems of scattering of ground vibrations on seismic barriers are considered, which is the case investigated in this paper. Therefore, material damping can be ignored in reducedscale experimental samples, and it does not matter what material (metal or plastic) is used for ultrasonic modelling purposes. 
In the present work, we describe the methodology of the approach and the results of the experimental investigations of propagation of Rayleigh wave pulses with the central frequency of $1 \mathrm{MHz}$, which corresponds to the scaling factor of about 1:1000, over arrays of periodic vertical holes earlier investigated in the full-scale experiments carried out in the real ground $^{16}$.

The small-scale replicas of real seismic arrays have been made on the surfaces of Aluminium rectangular blocks having the dimensions of 350x250x20 mm (each of these blocks can be considered as an elastic half space for Rayleigh waves at frequencies around 1 $\mathrm{MHz}$ ). The results of the measurements of transmission and reflection coefficients of ultrasonic Rayleigh waves over the above-mentioned reduced-scale replicas of periodic arrays of vertical holes demonstrate that the proposed approach is simple and efficient, and it helps to quickly evaluate the ability of a particular seismic array to suppress the transmitted Rayleigh waves. Part of the material described in this paper has been presented at the conference on noise and vibration engineering ${ }^{26}$.

\section{MANUFACTURING OF EXPERIMENTAL SAMPLES}

The experimental samples have been made of 20 mm-thick Aluminium plates having horizontal dimensions of $350 \times 250 \mathrm{~mm}$. Figure 1 shows a photograph of an Aluminium rectangular plate with an array of vertical holes drilled on its surface. A CNC (Computer Numerically Controlled) milling machine was used to produce arrays of vertical holes. The central frequency of Rayleigh wave pulses used in the experiments was $1 \mathrm{MHz}$.

First, an array of vertical holes was produced with the parameters providing a reducedscale model of the periodic array of vertical holes drilled in the real ground and investigated

in the work by Brule et $\mathrm{al}^{16}$. A scale factors have been calculated from the diameter, depth 
and lattice to wavelength $(\lambda=1.56 \mathrm{~m}$, according to the $50 \mathrm{~Hz}$ source used in Ref. 16) ratios of the experimental mesh ( $5 \mathrm{~m}$ deep self-stable holes of diameter $0.32 \mathrm{~m}$ with centre-to-centre spacing of $1.73 \mathrm{~m}), n_{D}=0.2, n_{h}=3.2, n_{a}=1.11$, respectively. A mesh of the reduced-scale model taking into account the scale factors calculated and the wavelength for a $1 \mathrm{MHz}$ Rayleigh wave in Aluminium, $\lambda_{R}$ (Rayleigh wave velocity in Aluminium, $v_{R}=2920 \mathrm{~m} / \mathrm{s}$ ), was made in square lattice of three lines of ten vertical holes $0.6 \mathrm{~mm}$ in diameter, $D, 9.2 \mathrm{~mm}$ in depth, $h$, (owing to the difficulty of drilling the holes with $0.6 \mathrm{~mm}$ in diameter, the depth $h$ was chosen to be $5 \mathrm{~mm}$ instead of $9.2 \mathrm{~mm}$ ) and $3.2 \mathrm{~mm}$ in lattice, $a$, (for convenience, we will use the following shortened notation for this sample: D06h50a32; similar notations will be also used for other experimental samples).

To investigate the influence of holes' sizes and spacing of reduced-scale model on the results, different meshes with different sizes of holes and lattice were produced in different samples; mesh of square lattice of $D=0.6 \mathrm{~mm}, h=5 \mathrm{~mm}$ and $a=\lambda_{R}$, (D06h50a29); mesh of rectangular lattice of $D=0.6 \mathrm{~mm}, h=5 \mathrm{~mm}$ and $(a, b)=(3.2,9) \mathrm{mm}$, (D06h50a32b90); mesh of square lattice of $D=1.2 \mathrm{~mm}, h=9.2 \mathrm{~mm}$ and $a=3.2 \mathrm{~mm}$, (D12h92a32) and mesh of square lattice of $D=1.2 \mathrm{~mm}, h=9.2 \mathrm{~mm}$ and $a=\lambda_{R}$, (D12h92a29). Figure 2 shows photographs of arrays of vertical holes drilled in Aluminium rectangular plates.

\section{EXPERIMENTAL SETUP}

The laboratory arrangement used for measurements of transmission and reflection coefficients of propagating Rayleigh wave pulses with the central frequency of $1 \mathrm{MHz}$, which corresponds to the value of scaling factor of about 1:1000, over small replicas of periodic arrays of vertical holes is shown in Fig. 3. Two Phoenix angle-beam piezoelectric ultrasonic transducers of $1 \mathrm{MHz}, 20 \mathrm{~mm}$ diameter crystal and L51xW27xH31 mm, were used to 
generate and receive ultrasonic Rayleigh waves on the surfaces of Aluminium rectangular blocks. A Sitescan150 ultrasonic testing system from Sonatest Ltd was used both to drive the transducer and to receive/display the ultrasonic signals. A Sonatest Data Management System version 3 (SDMS 3) was installed in the Laptop to interface and record the acquired data from Sitescan150 for further post processing.

Figure 4 represents a schematic of the experimental arrangement used for measuring the ultrasonic Rayleigh waves transmitted and reflected for different incident angles. The separation between the transmitter and the receiver was $d=5 \mathrm{~cm}$.

The reduced-scale models of periodic arrays of vertical holes were produced in the middle of one half of the Aluminium rectangular plates. Another half was used for the measurements of the propagation of ultrasonic Rayleigh waves over smooth surface (in the absence of holes) for reference purposes. Measurements were performed in transmission mode. The transducer connected to the Transmitter of Sitescan150 generated an ultrasonic Rayleigh wave pulse on the surface of an Aluminium plate. Another transducer was connected to the Receiver of Sitescan150 and placed behind the seismic barriers, separated by distance $d$, and received the ultrasonic Rayleigh waves generated by the transducer (transmitter).

For measurements of Rayleigh wave transmission, different incident angles, $\theta_{i}$, of ultrasonic Rayleigh waves were used. As angles of reception, the following angles were used: $\theta_{r}=-60^{\circ},-30^{\circ}, 0^{\circ}, 30^{\circ}$ and $60^{\circ}$. Due to the symmetry of the geometrical configurations of the seismic barriers used in the experiments, only angles of $\theta_{i}=0^{\circ}, 30^{\circ}$ and $60^{\circ}$ were considered for the incident waves. The positions and angles of the transducers (transmitter and receiver), are shown in Fig. 4(a).

With regard to the reflection of Rayleigh waves from the arrays of vertical holes, $30^{\circ}$ and $60^{\circ}$ incident angles have been chosen, and the receiver was placed as shown in Fig. 4(b). For 
reference purposes, the two transducers, transmitter and receiver, were located at the same distance, $d$, between them in the other half of the Aluminium rectangular plate (in the absence of drilled holes) for measuring the propagation of ultrasonic Rayleigh waves over smooth surface. The measurements were repeated several times for each configuration, and the results were averaged statistically.

\section{EXPERIMENTAL RESULTS AND DISCUSSION}

One of the aims of this investigation was to reproduce in a small scale the full-scale experimental measurements carried out in the real ground on Rayleigh wave transmission

through periodic arrays of vertical holes ${ }^{16}$, also termed 'seismic metamaterials' or 'seismic crystals'.

In the first step of the measurements, the transmitter and the receiver were placed in the normal position $\left(0^{\circ}\right)$. The measurements results for ultrasonic Rayleigh wave propagation over smooth surface and over an array of vertical holes, D06h50a32, as a reduced-scale model, at $1 \mathrm{MHz}$, of the full-scale experiments carried out in Ref. 16 are shown in Figs. 5 and 6 respectively.

The amplitude reduction factor for the above-mentioned model array of vertical holes was introduced as the ratio of the maximum value of the Rayleigh wave signal transmitted over the array of vertical holes and the maximum value of the Rayleigh wave signal transmitted over a smooth surface. The maximum values used for calculations of amplitude reduction factor were taken from full-wave rectifier signals. The amplitude reduction factor calculated from Figs. 5 and 6 is about 0.73, which shows a moderate attenuation of the signal transmitted through this array of vertical holes. This attenuation of ultrasonic Rayleigh waves transmitted through this type of array of vertical holes is substantially smaller than in the case 
of full-scale measurements ${ }^{16}$, where the signal hardly reaches the second row of boreholes. A more detailed comparison is not possible because in the above-mentioned Ref. 16 a point source of Rayleigh waves has been used, whereas in the present paper wedge ultrasonic transducers have been used that generate quasi-plane Rayleigh waves in their near field.

For oblique incidence, the transmitter was placed at the angles $\theta_{i}=30^{\circ}$ and $60^{\circ}$, while the receiver still was in the normal position. In what follows only the full-wave rectifier signals are presented. The corresponding measurement results are shown in Fig. 7.

The next measurements were to measure the reflection coefficients from the same model array of vertical holes. In the case of Rayleigh wave reflections from the model array, two pairs of incidence and reflection angles have been used, $\left(\theta_{i}=30^{\circ}, \theta_{r}=30^{\circ}\right)$, and $\left(\theta_{i}=60^{\circ}, \theta_{r}\right.$ $\left.=60^{\circ}\right)$. The reflected signals are shown in Fig. 8.

To obtain the value of the reflection coefficient, the amplitude of the reflected wave must be divided by the amplitude of the incident wave. In this study, the amplitude of the ultrasonic Rayleigh wave propagation over smooth surface has been used as the amplitude of the incident wave. The reflection coefficients calculated in this way are 0.09 and 0.04 for $\left(\theta_{i}\right.$ $\left.=30^{\circ}, \theta_{r}=30^{\circ}\right)$, and $\left(\theta_{i}=60^{\circ}, \theta_{r}=60^{\circ}\right)$ respectively.

In order to study the effect of the lattice structure on the results, two arrays of vertical holes with the same diameter, $D=0.6 \mathrm{~mm}$, and depth, $h=5 \mathrm{~mm}$, have been tested. The first one corresponded to an array with rectangular lattice, $(a, b)=(3.2,9) \mathrm{mm}$, D06h50a32b90, and the second one corresponded to an array with the square lattice, with the lattice constant $a=$ $\lambda_{R}=2.9 \mathrm{~mm}$ being equal to the wavelength of Rayleigh wave in Aluminium at $1 \mathrm{MHz}$, D06h50a29. Figures 9 and 10 show the full-wave rectifier signals of ultrasonic Rayleigh waves and their corresponding frequency spectra for the propagation over smooth surface and over the array of rectangular lattice, D06h50a32b90; as well as over smooth surface and over 
the array of square lattice, D06h50a29, respectively. The transmitter and the receiver were placed in the normal position, $\theta_{i}=0$ and $\theta_{r}=0$.

The calculated amplitude reduction factors are 0.67 and 0.61 for the rectangular lattice, D06h50a32b90, and for the square lattice, D06h50a29, respectively. As it can be seen, these new samples of arrays of vertical holes do not bring further noticeable reductions to the transmitted Rayleigh waves in comparison with the first array of vertical holes, D06h50a32. For the case of oblique incidence $\left(\theta_{i}=30^{\circ}\right.$ and $\left.60^{\circ}\right)$ and for the receiver in normal position, the measurement results for both arrays, rectangular and square lattices, are shown in Figs. 11 and 12 respectively.

For measurements of Rayleigh wave reflection from arrays (rectangular lattice, D06h50a32b90 and square lattice, D06h50a29), two incident angles have been investigated initially. The measurement results are shown in Figs. 13 and 14 respectively.

The reflection coefficients for rectangular lattice, D06h50a32b90, are 0.10 and 0.03 for $\left(\theta_{i}\right.$ $\left.=30^{\circ}, \theta_{r}=30^{\circ}\right)$ and for $\left(\theta_{i}=60^{\circ}, \theta_{r}=60^{\circ}\right)$ respectively. And for the square lattice, D06h50a29, they were 0.08 and 0.04 for $\left(\theta_{i}=30^{\circ}, \theta_{r}=30^{\circ}\right)$ and for $\left(\theta_{i}=60^{\circ}, \theta_{r}=60^{\circ}\right)$ respectively.

Resuming the above, very similar results have been obtained for all of the abovementioned three samples of arrays having the same diameter and depth of holes, but different lattice parameters. These rather modest results stimulated us to produce two more arrays of square lattice, with the diameter of holes increased up to $1.2 \mathrm{~mm}$ and depth up to $9.2 \mathrm{~mm}$ and with the lattice parameters $a=3.2 \mathrm{~mm}$ and $2.9 \mathrm{~mm}$ respectively. The transmitter and the receiver were placed in the normal position. The results of the measurements of ultrasonic Rayleigh wave propagation over smooth surface and over square lattice, D12h92a32, as well as over smooth surface and over square lattice, D12h92a29, are shown in Figs. 15 and 16 respectively. 
The amplitude reduction factors are the same in both cases and are equal to 0.36 . It can be seen from Figs. 15 and 16 that there is an increase in attenuation of the signal transmitted through both these arrays of square lattice. These results demonstrate that the attenuation of Rayleigh waves depends strongly on the size of vertical holes. This means that the arrays of vertical holes with bigger diameter and deeper holes bring better reduction of the signal than arrays of vertical holes with small diameter and depth.

For measurements of Rayleigh wave reflection, two incident angles were considered as in the previous cases, with the corresponding reflection angles being equal to the incident angles: $\left(\theta_{i}=30^{\circ}, \theta_{r}=30^{\circ}\right)$ and $\left(\theta_{i}=60^{\circ}, \theta_{r}=60^{\circ}\right)$. The results of the measurements of the reflection coefficients of Rayleigh waves from the square lattice, D12h92a32 and from the square lattice D12h92a29 are shown in Figs. 17 and 18 respectively.

It can be shown that the reflection coefficients from the square lattice, D12h92a32, are 0.20 and 0.15 for $30^{\circ}$ and $60^{\circ}$ respectively. And the reflection coefficients from the square lattice, D12h92a29, are 0.20 and 0.11 for $30^{\circ}$ and $60^{\circ}$ respectively. Approximately the same values of reflection coefficients have been observed for both arrays with different lattice parameters.

\section{CONCLUSIONS}

It has been demonstrated in this paper that reduced-scale ultrasonic modelling of Rayleigh wave interaction with periodic arrays of vertical holes used as seismic barriers can be a useful tool for experimental investigations of the properties of different types of seismic barriers as mitigation measures against railway- and traffic-induced ground vibrations.

The advantage of reduced-scale ultrasonic modelling of periodic arrays of vertical holes over full-scale experimental measurements is that it is compact and much less expensive. It is 
easy to manufacture numerous experimental samples to model different configurations of the arrays.

The relationship between geometrical dimensions of real seismic barriers and their reduced-scale replicas depends on the relationship between the real characteristic frequency of ground vibrations and the central frequency of ultrasonic signal in a model sample, as well as on Rayleigh wave velocities in the ground and in the material of the experimental sample.

One of the disadvantages of reduced-scale ultrasonic modelling is that standard ultrasonic transducers used for generation and reception of Rayleigh waves are relatively narrow band devices designed for specific central frequencies, in contrast to real sources of railway- and traffic-induced ground vibrations that are broadband, typically between 10 and $100 \mathrm{~Hz}$. Broadband sources of ground vibrations can be modelled using measurements with several pairs of ultrasonic transducers having different central frequencies.

Regarding the specific measurements on a number of Aluminium samples modelling the periodic arrays of vertical holes with different geometrical parameters, it can be concluded that, for the parameters used in the experiments, periodic arrays of vertical holes provide rather moderate suppression of transmitted Rayleigh waves.

\section{ACKNOWLEDGEMENTS}

The research reported here has been supported by EPSRC grant EP/K038214/1.

\section{REFERENCES}

1. G. Segol, C.Y. Lee and J.F. Abel, "Amplitude reduction of surface waves by trenches", J. Eng. Mech. Div.: Proc. ASCE, 104(3), 621-641, (1978). 
2. D.E. Beskos, B. Dasgupta and I.G. Vardoulakis, "Vibration isolation using open or filled trenches. Part I: 2-D homogeneous soil", Comput. Mech., 1, 43-63, (1986).

3. K. Leung, I.G. Vardoulakis and D.E. Beskos, "Vibration isolation using open or filled trenches. Part III: 2-D nonhomogeneous soil", Comput. Mech., 7, 137-148, (1990).

4. S. Ahmad and T.M. Al-Hussaini, "Simplified design for vibration screening by open and in-filled trenches", J. Geotech. Eng.: Proc. ASCE, 117(1), 67-88, (1991).

5. R. Klein, H. Antes and D. Le Houédec, "Efficient 3D modelling of vibration isolation by open trenches", Comput. Struct., 64, 809-817, (1997).

6. A. Karlström and A. Boström, "Efficiency of trenches along railways for trains moving at sub-or supersonic speeds", Soil Dyn. Earthq. Eng., 27, 625-641, (2007).

7. D. Ulgen, O.L. Ertugrul and M.Y. Ozkan, "Measurement of ground borne vibrations for foundation design and vibration isolation of a high-precision instrument", Measurement, 93, 385-396, (2016).

8. A. Garinei, G. Risitano, L. Scappaticci and F. Castellani, "An optimized method to evaluate the performance of trench isolation for railway-induced vibration", Measurement, 94, 92-102, (2016).

9. $\quad$ R. Hildebrand, "Asymptotic analysis of hard wave barriers in soil", Soil Dyn. Earthq. Eng., 23(7), 143158, (2003).

10. L. Andersen and S.R.K. Nielsen, "Reduction of ground vibration by means of barriers or soil improvement along a railway track", Soil Dyn. Earthq. Eng., 25, 701-716, (2005).

11. P. Coulier, V. Cuéllar, G. Degrande and G. Lombaert, "Experimental and numerical evaluation of the effectiveness of a stiff wave barrier in the soil", Soil Dyn. Earthq. Eng., 77, 238-253, (2015).

12. J. Aviles and F.J. Sanchez-Sesma, "Foundation isolation from vibrations using piles as barriers", J. Eng. Mech. Div.: Proc. ASCE, 114(11), 1854-1870, (1988).

13. S.E. Kattis, D. Polyzos and D.E. Beskos, "Vibration isolation by a row of piles using a 3-D frequency domain BEM", Int. J. Numer. Methods Eng., 46, 713-728, (1999).

14. S.E. Kattis, D. Polyzos and D.E. Beskos, "Modelling of pile wave barriers by effective trenches and their screening effectiveness", Soil Dyn. Earthq. Eng., 18(1), 1- 10, (1999).

15. G.Y. Gao, Z.Y. Li, C. Qiu and Z.Q. Yue, "Three-dimensional analysis of rows of piles as passive barriers for ground vibration isolation", Soil Dyn. Earthq. Eng., 26(11), 1015-1027, (2006).

16. S. Brule, E.H. Javelaud, S. Enoch and S. Guenneau, "Experiments on seismic metamaterials: molding surface waves", Phys. Rev. Lett., 112(13), 133901(5), (2014). 
17. V.V. Krylov, "Control of traffic-induced ground vibrations by placing heavy masses on the ground surface", J. Low Freq. Noise Vib. Act. Control, 26 (4), 311-320, (2007).

18. A. Dijckmans, P. Coulier, J. Jiang, M.G.R. Toward, D.J. Thompson, G. Degrande and G. Lombaert, "Mitigation of railway induced ground vibration by heavy masses next to the track", Soil Dyn. Earthq. Eng., 75, 158-170, (2015).

19. S.V. Biryukov, Yu.V. Gulyaev, V.V. Krylov and V.P. Plessky, Surface acoustic waves in inhomogeneous media, Springer, Berlin, (1995).

20. A. Alzawi and M.H. El Naggar, "Full scale experimental study on vibration scattering using open and infilled (geofoam) wave barriers", Soil Dyn. Earthq. Eng., 31(3), 306-317, (2011).

21. E. Çelebi, S. Firat, G. Beyhan, I. Çankaya, I. Vural and O. Kirtel, "Field experiments on wave propagation and vibration isolation by using wave barriers", Soil Dyn. Earthq. Eng., 29(5), 824-833, (2009).

22. J.P. Parekh and H.-S. Tuan, "Reflection and bulk-wave conversion of Rayleigh wave at a single shallow groove", J. Appl. Phys., 48(3), 994-1003, (1977).

23. B.R. Tittmann, L.A. Ahlberg and A.K. Mal, "Rayleigh wave diffraction from surface-brealking discontinuities", Appl. Phys. Lett., 49(20), 1333-1335, (1986).

24. S.Z. Zharylkapov and V.V. Krylov, "Scattering of Rayleigh waves by a groove of arbitrary depth", Soviet Physics - Acoustics, 33(5), 509-511, (1987).

25. R.J. Blake and L.J. Bond, "Rayleigh wave scattering from surface features: up-steps and troughs", Ultrasonics, 30(4), 255-265, (1992).

26. A. Azbaid El Ouahabi and V.V. Krylov, "Reduced-scale ultrasonic modelling of Rayleigh wave transmission over seismic barriers", 27th Int. Conf. Noise Vibr. Eng. (ISMA 2016), 1829-1842, (2016). 


\section{List of Figure captions}

Fig. 1. Photograph of an Aluminium rectangular plate with an array of vertical holes (on the left); the right-hand side of the plate is used for measurements of a reference signal transmission.

Fig. 2. Close up photographs of the arrays of vertical holes drilled on the surface of Aluminium rectangular plates: (a) D06h50a32; (b) D06h50a29; (c) D12h92a32; (d) D12h92a29 and (e) D06h50a32b90.

Fig. 3. Photograph of the experimental setup showing the Perspex wedge transducers of $1 \mathrm{MHz}$, an Aluminium rectangular block with an array of vertical holes drilled on the surface, a Sitescan150, and a Laptop with SDMS 3 installed.

Fig. 4. Schematic of the experimental arrangement for different angles showing the position and the angles of the transmitter $(\mathrm{T})$ and the receiver (R) for measuring the transmission and reflection of ultrasonic Rayleigh waves on the surfaces of Aluminium rectangular plates: (a) transmission over the array of vertical holes, (b) reflection from the array of vertical holes.

Fig. 5. The received signals of ultrasonic Rayleigh waves propagating over a smooth surface at $\theta_{i}=0$ and $\theta_{r}=0$ : (a) the time-domain waveform, (b) the 
full-wave rectifier, (c) the expanded time-domain waveform, and (d) the corresponding frequency spectrum.

Fig. 6. The received signals of ultrasonic Rayleigh wave propagating over the array of vertical holes, D06h50a32, as a reduced-scale model of the seismic array of boreholes experimentally investigated in Ref. 16; $\theta_{i}=0$ and $\theta_{r}=0$ : (a) the time-domain waveform, (b) the full-wave rectifier, (c) the expanded time-domain waveform, and (d) the corresponding frequency spectrum.

Fig. 7. The full-wave rectifier signal of ultrasonic Rayleigh wave propagating over the array of vertical holes, D06h50a32; receiver at normal position, $\theta_{r}=0$ : (a) Transmitter at $\theta_{i}=30^{\circ}$, (b) Transmitter at $\theta_{i}=60^{\circ}$.

Fig. 8. The full-wave rectifier signal of ultrasonic Rayleigh wave reflecting from an array of vertical holes, D06h50a32: (a) $\theta_{i}=30^{\circ}, \theta_{r}=30^{\circ}$, (b) $\theta_{i}=60^{\circ}$, $\theta_{r}=60^{\circ}$.

Fig. 9. The received signals of ultrasonic Rayleigh waves, $\theta_{i}=0$ and $\theta_{r}=0$ : (a) the full wave rectifier signal transmitted over a smooth surface, and (b) the corresponding Frequency spectrum; (c) the full wave rectifier signal transmitted over the rectangular lattice $(a, b)=(3.2,9) \mathrm{mm}$, D06h50a32b90, and (d) the corresponding Frequency spectrum. 
Fig. 10. The received signals of ultrasonic Rayleigh waves, $\theta_{i}=0$ and $\theta_{r}=0$ : (a) the full wave rectifier signal transmitted over a smooth surface, and (b) the corresponding Frequency spectrum; (c) the full wave rectifier signal transmitted over the square lattice, D06h50a29, and (d) the corresponding Frequency spectrum.

Fig. 11. The full-wave rectifier signal of ultrasonic Rayleigh wave propagating over the rectangular lattice, D06h50a32b90; receiver at the normal position, $\theta_{r}=0^{\circ}$ : (a) Transmitter at $\theta_{i}=30^{\circ}$, (b) Transmitter at $\theta_{i}=60^{\circ}$.

Fig. 12. The full-wave rectifier signal of ultrasonic Rayleigh wave propagating over the square lattice, D06h50a29; receiver at normal position, $\theta_{r}=0^{\circ}$ : (a) Transmitter at $\theta_{i}=30^{\circ}$, (b) Transmitter at $\theta_{i}=60^{\circ}$.

Fig. 13. Full-wave rectifier signal of ultrasonic Rayleigh wave reflection from the rectangular lattice D06h50a32b90: (a) $\theta_{i}=30^{\circ}, \theta_{r}=30^{\circ}$, (b) $\theta_{i}=60^{\circ}, \theta_{r}=$ $60^{\circ}$.

Fig. 14. Full-wave rectifier signal of ultrasonic Rayleigh wave reflection from square lattice, D06h50a29. (a) $\theta_{i}=30^{\circ}, \theta_{r}=30^{\circ}$, (b) $\theta_{i}=60^{\circ}, \theta_{r}=60^{\circ}$.

Fig. 15. Signals of ultrasonic Rayleigh waves, $\theta_{i}$ and $\theta_{r}=0^{\circ}$ : (a) Full wave rectifier signal transmitted over a smooth surface, (b) The corresponding frequency spectrum, (c) Full wave rectifier signal transmitted over a square lattice D12h92a32, and (d) The corresponding frequency spectrum. 
Fig. 16. Signals of ultrasonic Rayleigh waves, $\theta_{i}$ and $\theta_{r}=0^{\circ}$ : (a) Full wave rectifier signal transmitted over a smooth surface, (b) The corresponding frequency spectrum, (c) Full wave rectifier signal transmitted over a square lattice D12h92a29, and (d) The corresponding frequency spectrum.

Fig. 17. Full-wave rectifier signal of ultrasonic Rayleigh wave reflection from the square lattice, D12h92a32: (a) $\theta_{i}=30^{\circ}, \theta_{r}=30^{\circ}$, (b) $\theta_{i}=60^{\circ}, \theta_{r}=60^{\circ}$.

Fig. 18. Full-wave rectifier signal of ultrasonic Rayleigh wave reflection from the square lattice, D12h92a29: (a) $\theta_{i}=30^{\circ}, \theta_{r}=30^{\circ}$, (b) $\theta_{i}=60^{\circ}, \theta_{r}=60^{\circ}$. 


\section{Figures}

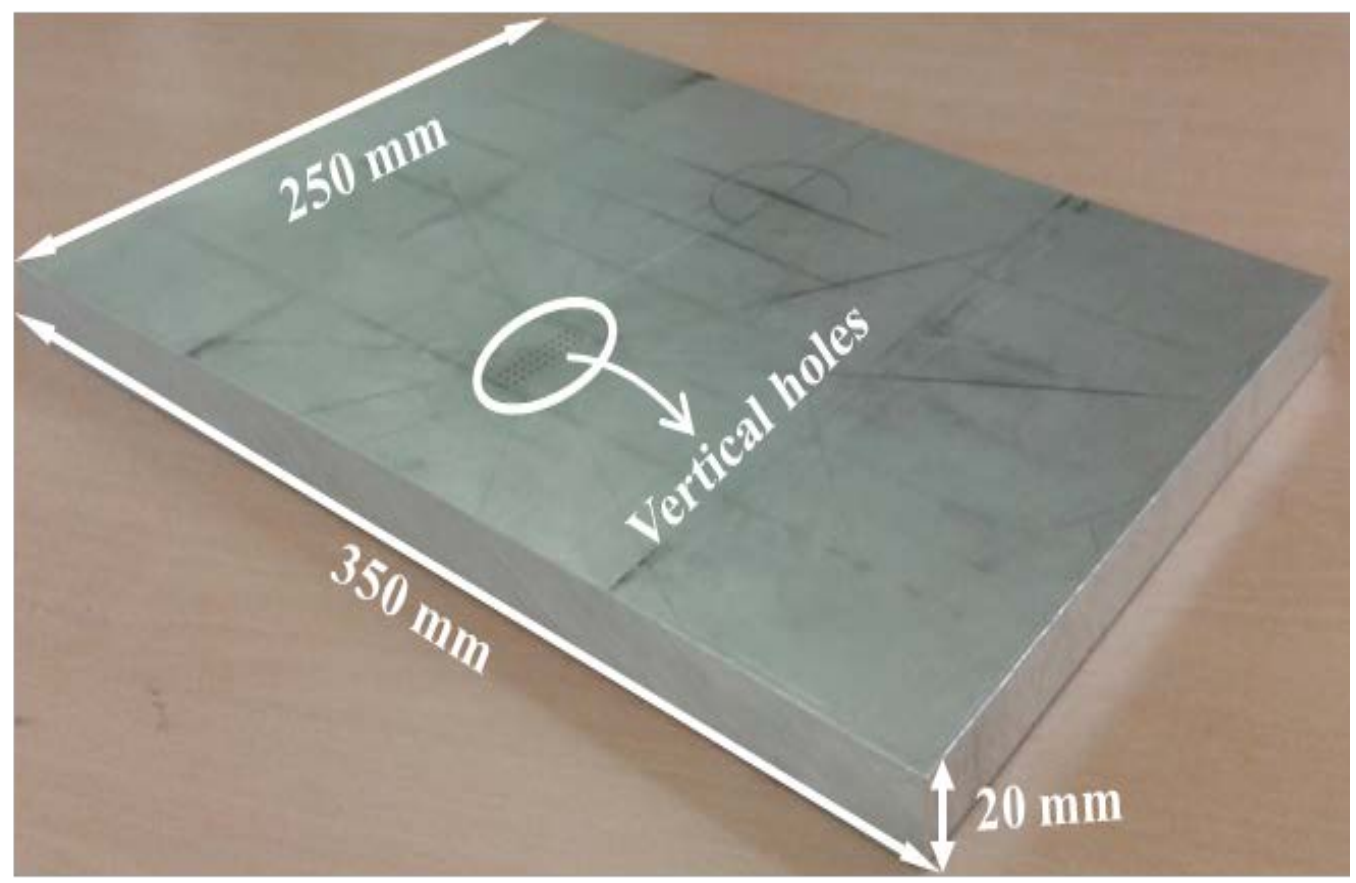

Fig. 1. Photograph of an Aluminium rectangular plate with an array of vertical holes (on the left); the right-hand side of the plate is used for measurements of a reference signal transmission. 
(a)

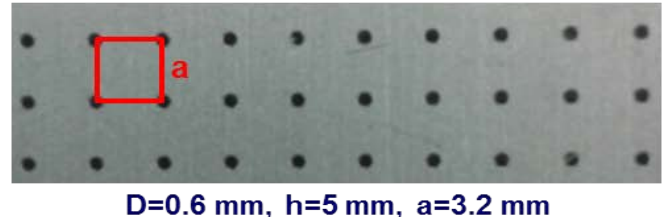

(c)

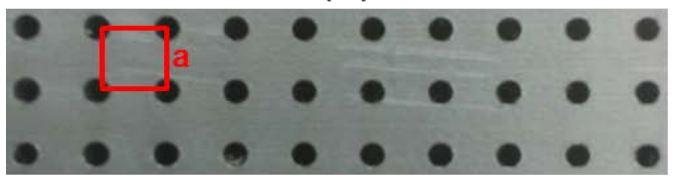

$\mathrm{D}=1.2 \mathrm{~mm}, \mathrm{~h}=9.2 \mathrm{~mm}, \mathrm{a}=3.2 \mathrm{~mm}$ (b)

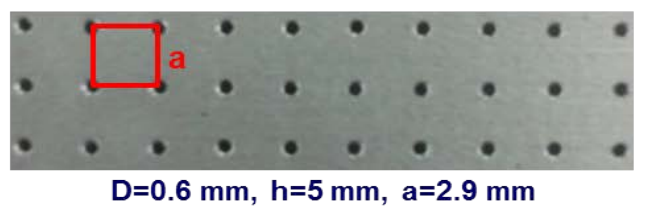

(d)

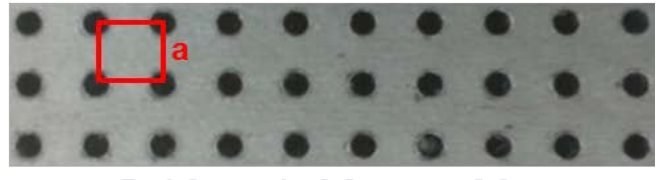

$\mathrm{D}=1.2 \mathrm{~mm}, \mathrm{~h}=9.2 \mathrm{~mm}, \mathrm{a}=2.9 \mathrm{~mm}$

(e)

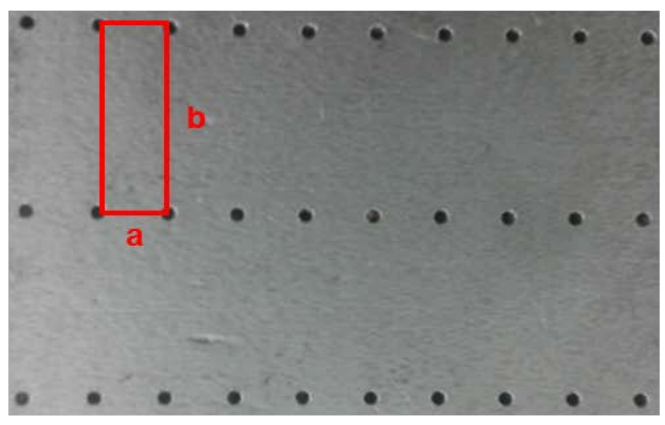

$D=0.6 \mathrm{~mm}, \mathrm{~h}=5 \mathrm{~mm}, \mathrm{a}=3.2 \mathrm{~mm}, \mathrm{~b}=9 \mathrm{~mm}$

Fig. 2. Close up photographs of the arrays of vertical holes drilled on the surface of Aluminium rectangular plates: (a) D06h50a32; (b) D06h50a29; (c) D12h92a32; (d) D12h92a29 and (e) D06h50a32b90. 


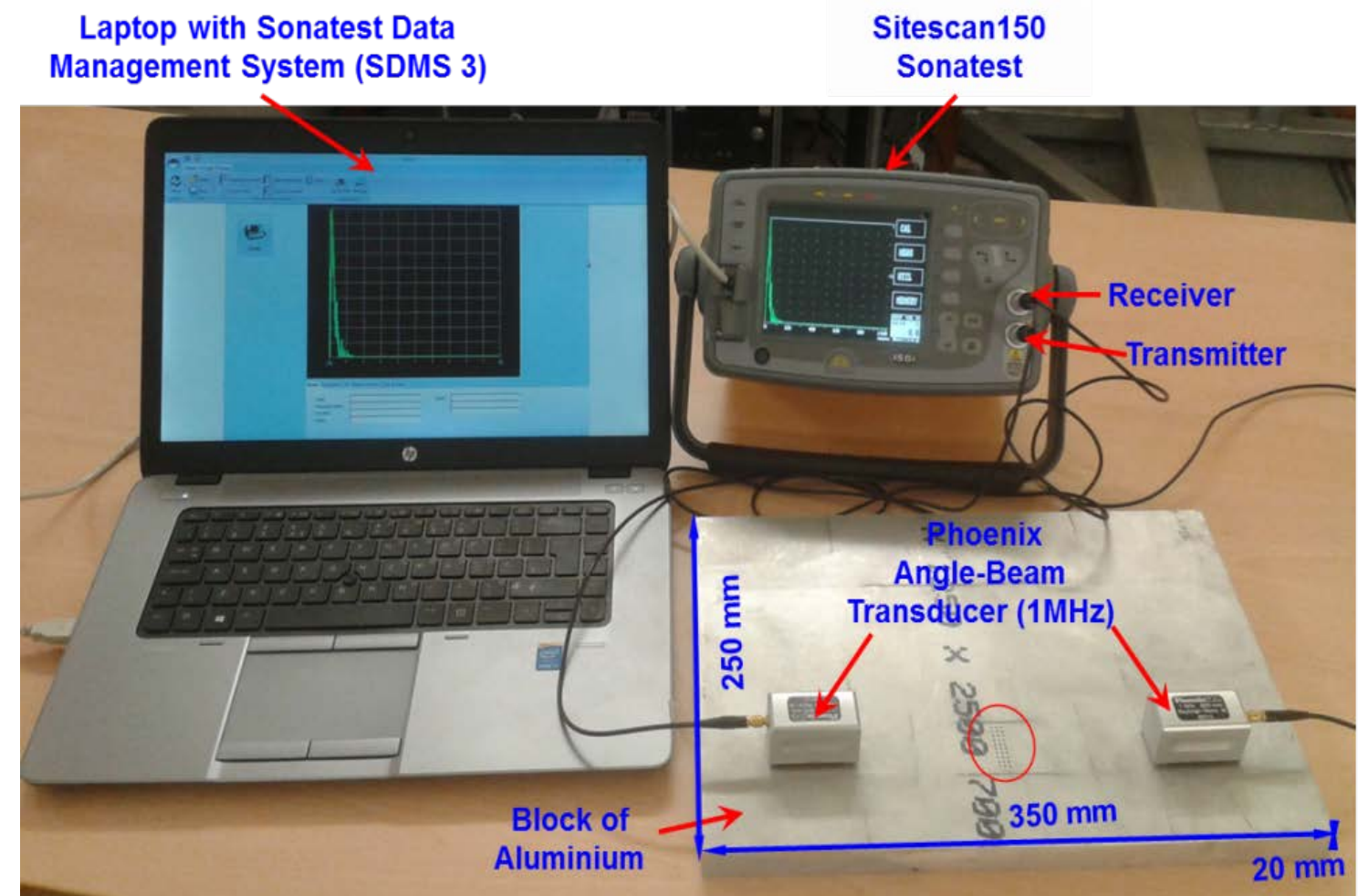

Fig. 3. Photograph of the experimental setup showing the Perspex wedge transducers of $1 \mathrm{MHz}$, an Aluminium rectangular block with an array of vertical holes drilled on the surface, a Sitescan150, and a Laptop with SDMS 3 installed. 

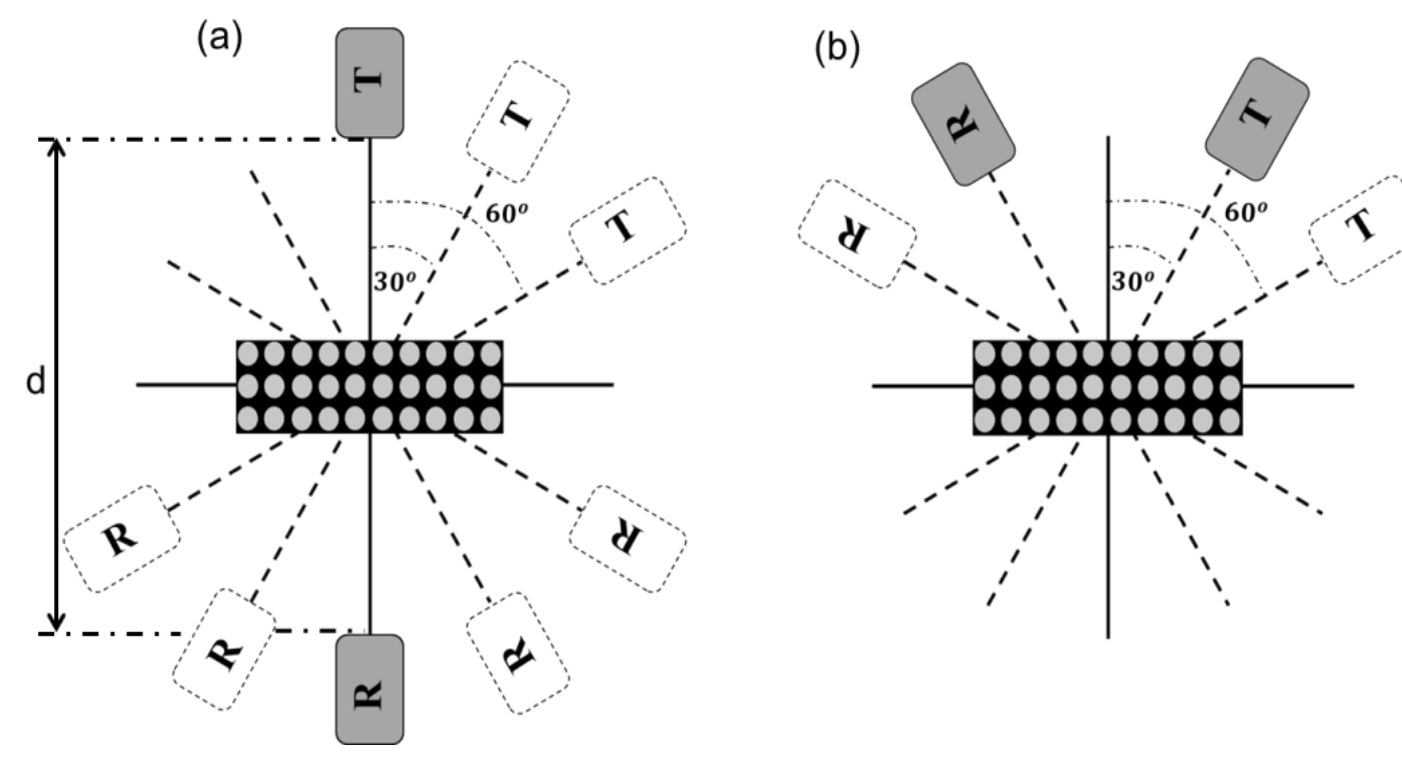

Fig. 4. Schematic of the experimental arrangement for different angles showing the position and the angles of the transmitter $(\mathrm{T})$ and the receiver $(\mathrm{R})$ for measuring the transmission and reflection of ultrasonic Rayleigh waves on the surfaces of Aluminium rectangular plates: (a) transmission over the array of vertical holes, (b) reflection from the array of vertical holes. 
(a)

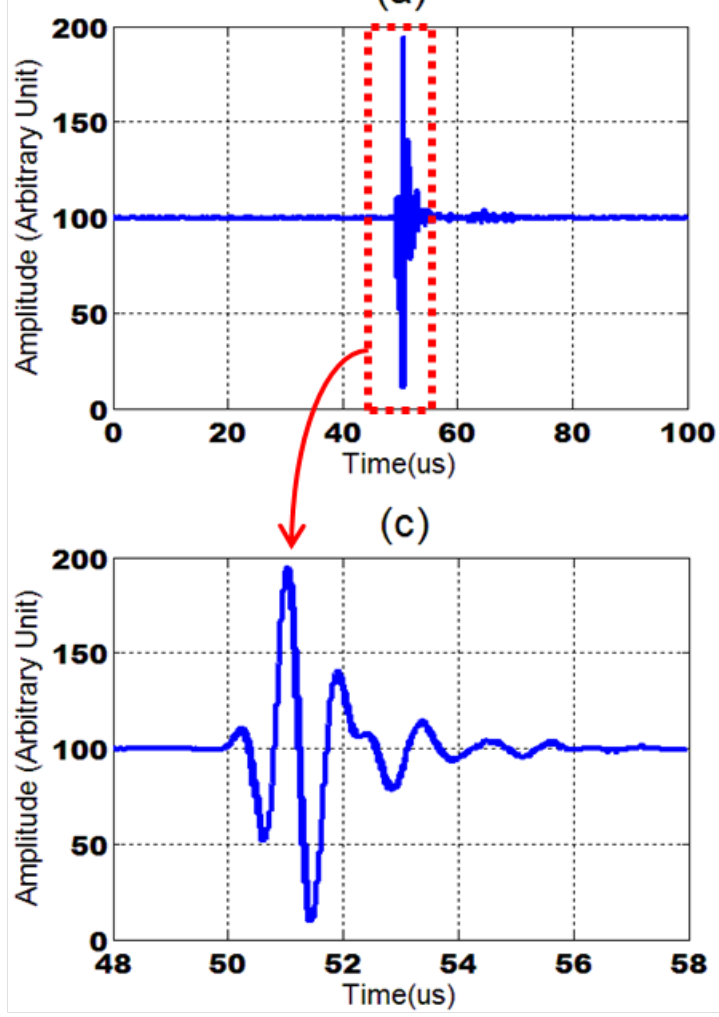

(b)

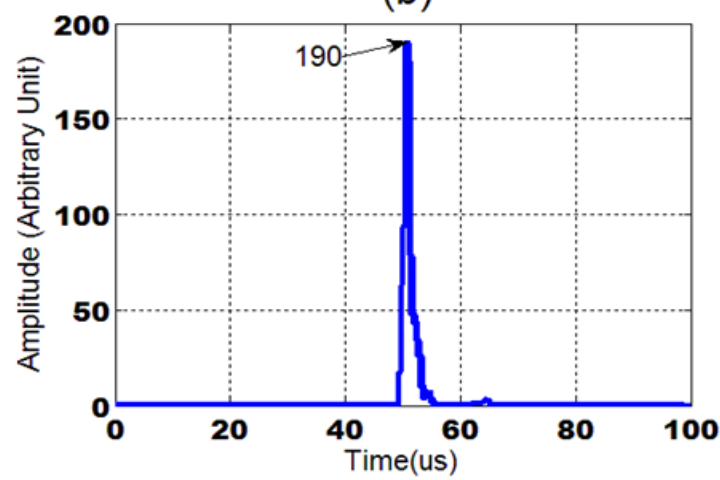

(d)

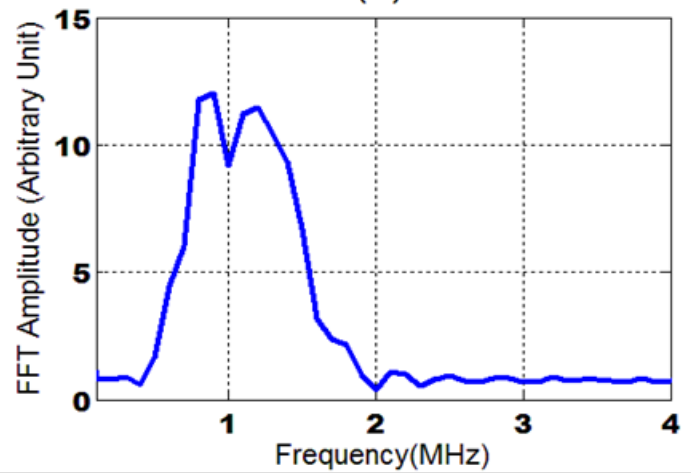

Fig. 5. The received signals of ultrasonic Rayleigh waves propagating over a smooth surface at $\theta_{i}=0$ and $\theta_{r}=0$ : (a) the time-domain waveform, (b) the full-wave rectifier, (c) the expanded time-domain waveform, and (d) the corresponding frequency spectrum. 
(a)

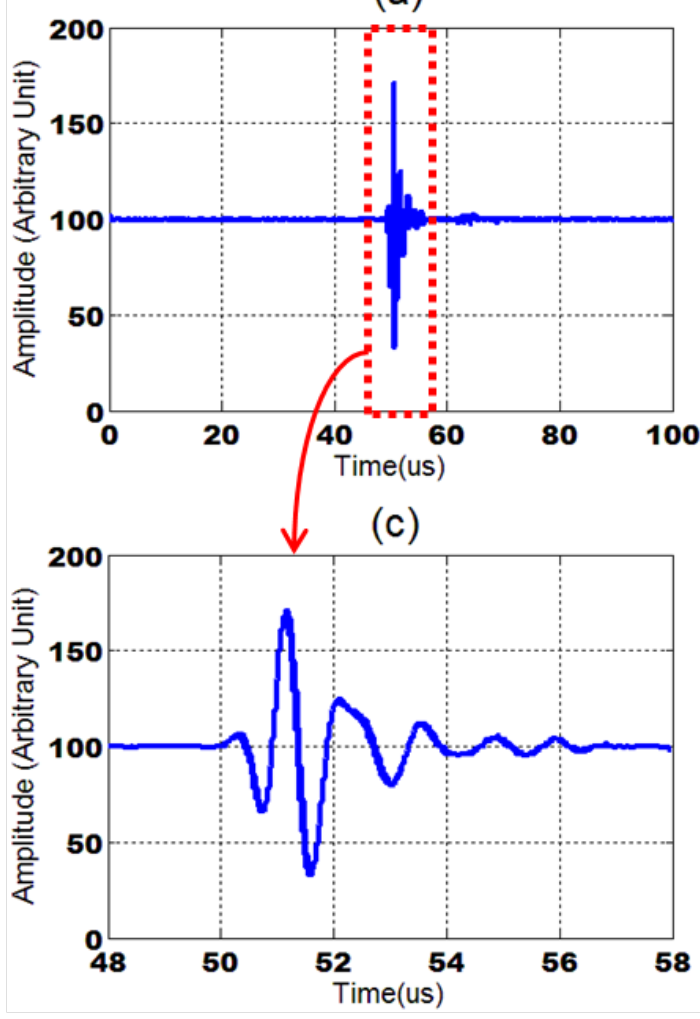

(b)

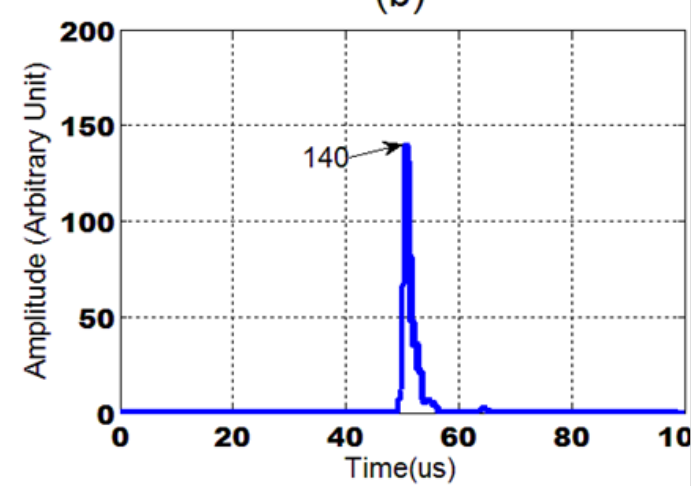

(c)

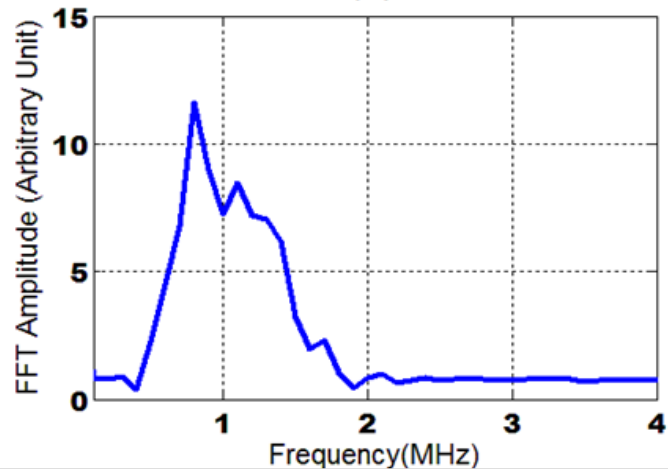

Fig. 6. The received signals of ultrasonic Rayleigh wave propagating over the array of vertical holes, D06h50a32, as a reduced-scale model of the seismic array of boreholes experimentally investigated in Ref. 16; $\theta_{i}=0$ and $\theta_{r}=0$ : (a) the time-domain waveform, (b) the full-wave rectifier, (c) the expanded time-domain waveform, and (d) the corresponding frequency spectrum. 
(a)

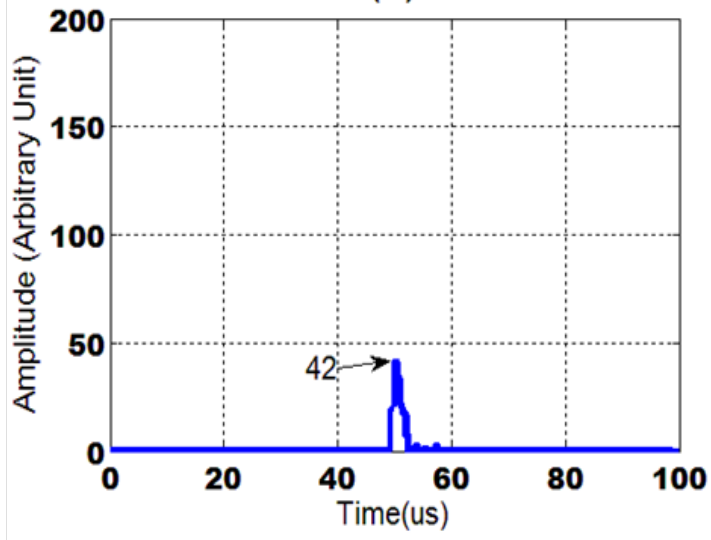

(b)

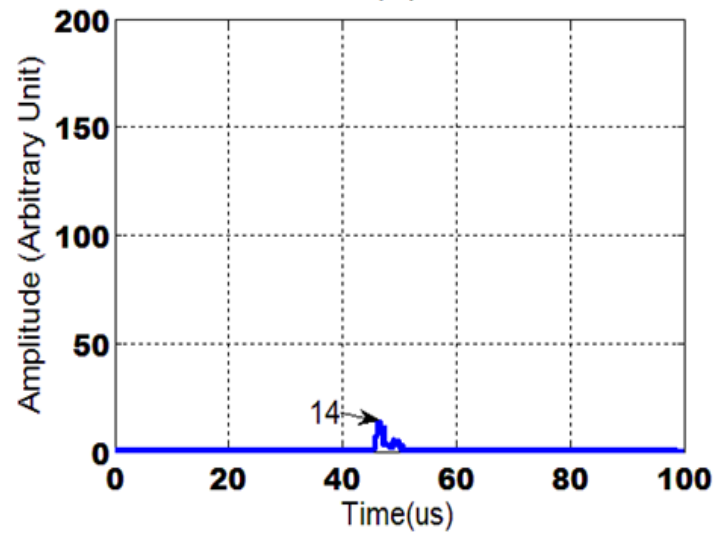

Fig. 7. The full-wave rectifier signal of ultrasonic Rayleigh wave propagating over the array of vertical holes, D06h50a32; receiver at normal position, $\theta_{r}=0$ : (a) Transmitter at $\theta_{i}=30^{\circ}$, (b) Transmitter at $\theta_{i}=60^{\circ}$. 
(a)

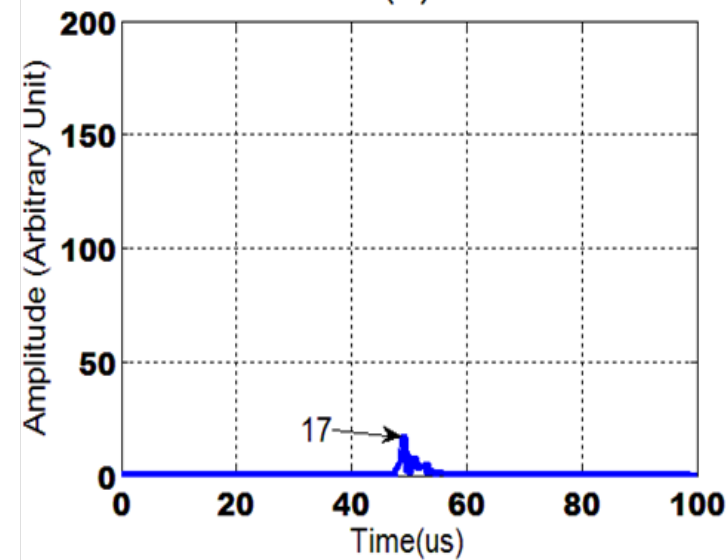

(b)

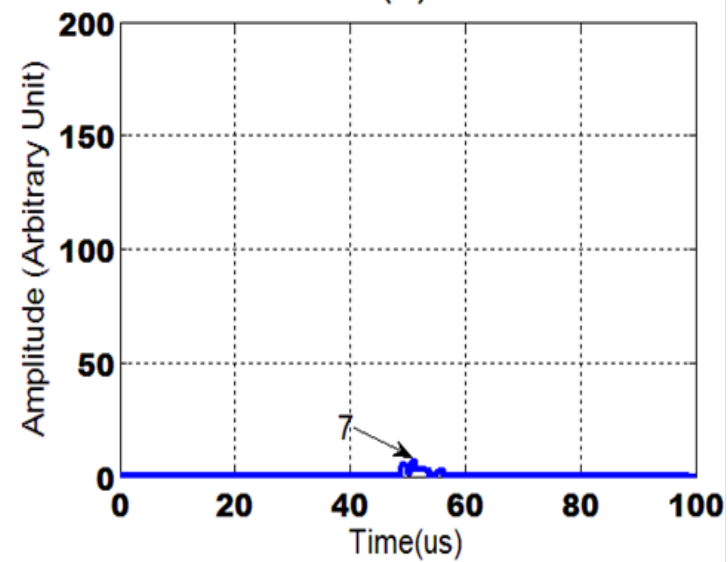

Fig. 8. The full-wave rectifier signal of ultrasonic Rayleigh wave reflecting from an array of vertical holes, D06h50a32: (a) $\theta_{i}=30^{\circ}, \theta_{r}=30^{\circ}$, (b) $\theta_{i}$ $=60^{\circ}, \theta_{r}=60^{\circ}$. 
(a)

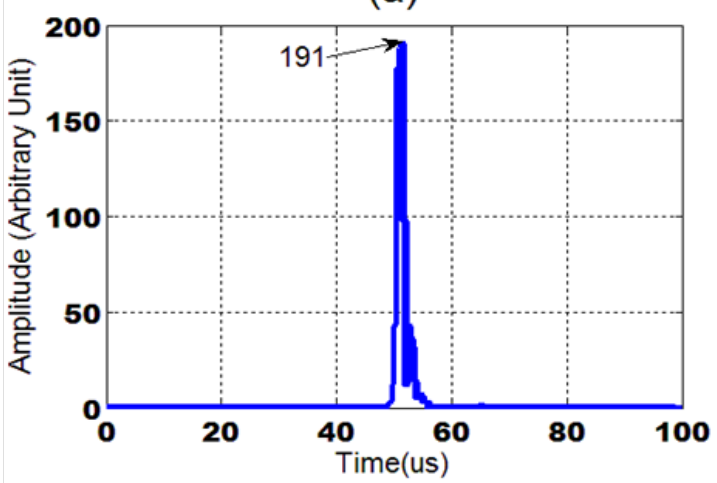

(c)

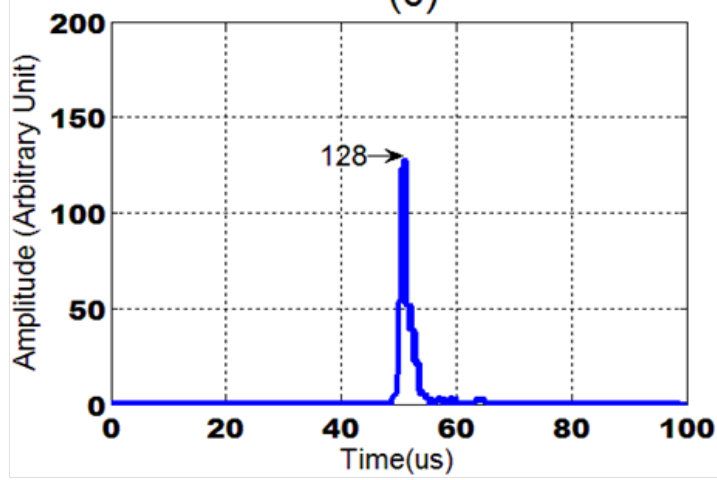

(b)

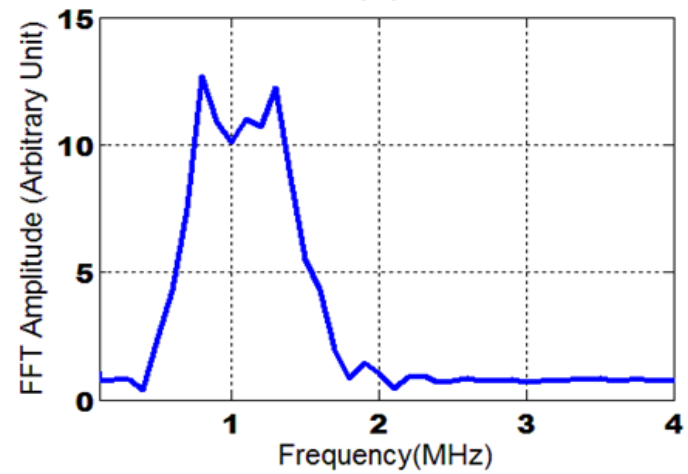

(d)

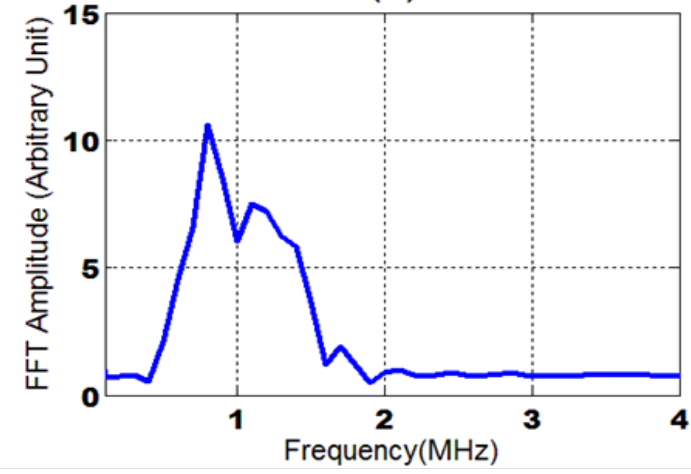

Fig. 9. The received signals of ultrasonic Rayleigh waves, $\theta_{i}=0$ and $\theta_{r}=0$ : (a) the full wave rectifier signal transmitted over a smooth surface, and (b) the corresponding Frequency spectrum; (c) the full wave rectifier signal transmitted over the rectangular lattice $(a, b)=(3.2,9) \mathrm{mm}$, D06h50a32b90, and (d) the corresponding Frequency spectrum. 
(a)

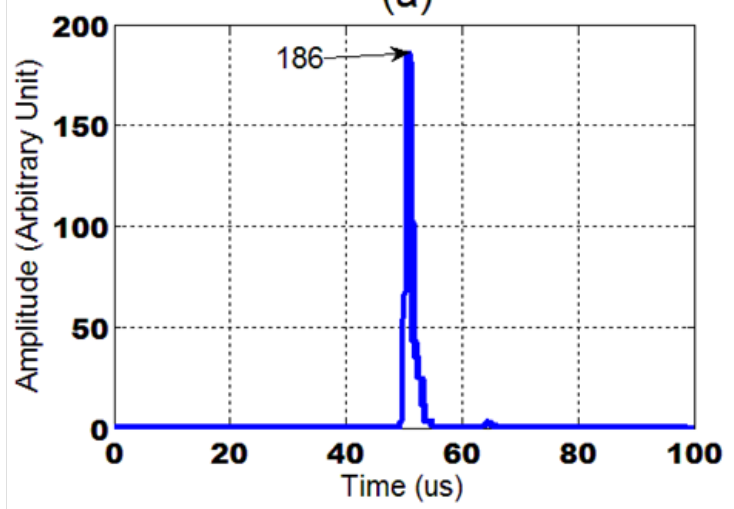

(c)

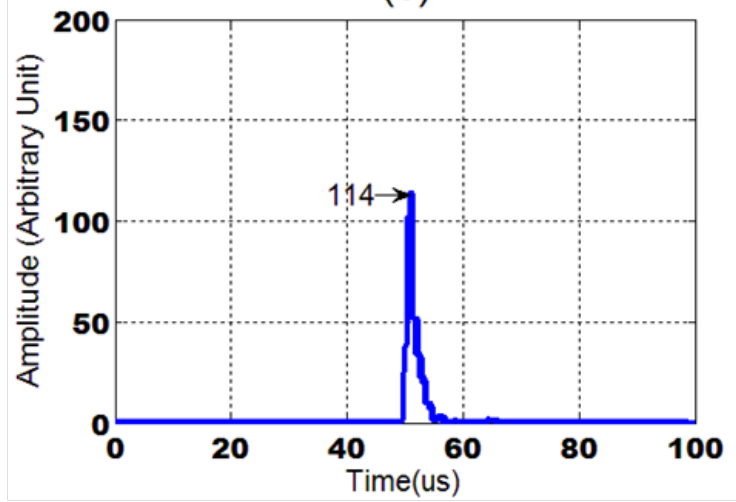

(b)

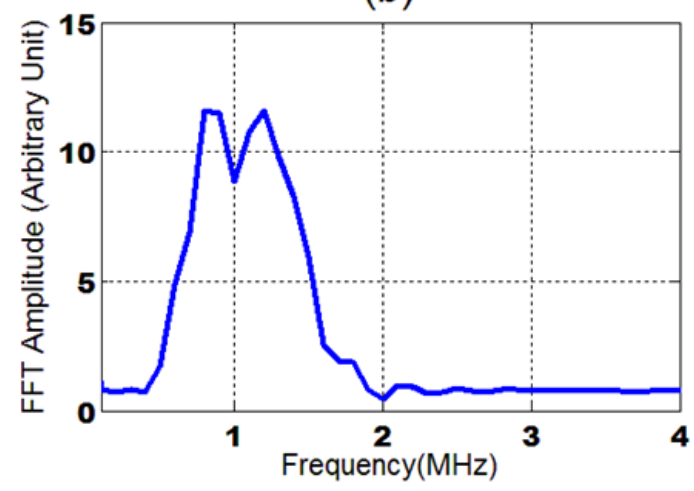

(d)

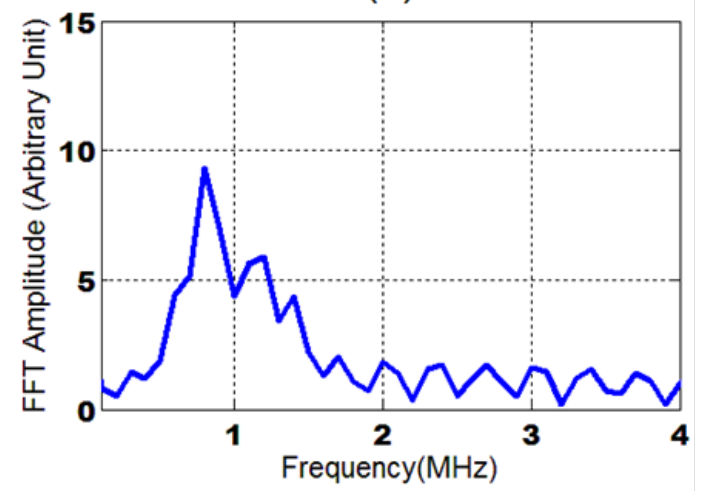

Fig. 10. The received signals of ultrasonic Rayleigh waves, $\theta_{i}=0$ and $\theta_{r}=0$ : (a) the full wave rectifier signal transmitted over a smooth surface, and (b) the corresponding Frequency spectrum; (c) the full wave rectifier signal transmitted over the square lattice, D06h50a29, and (d) the corresponding Frequency spectrum. 
(a)

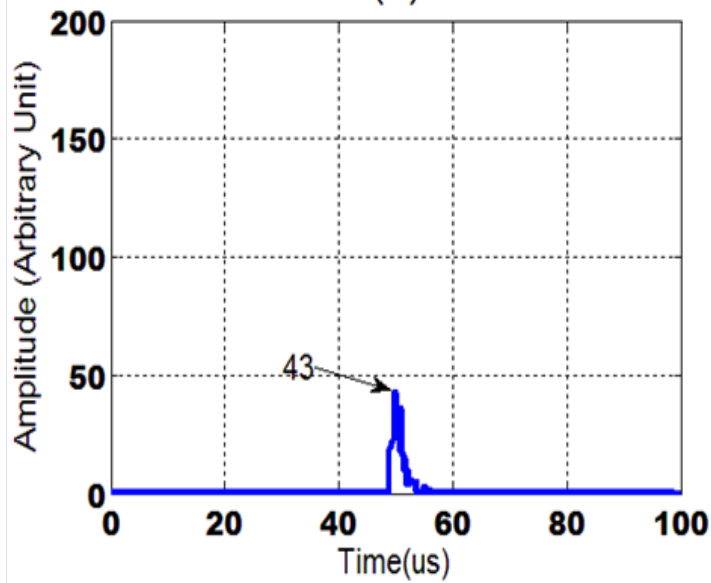

(b)

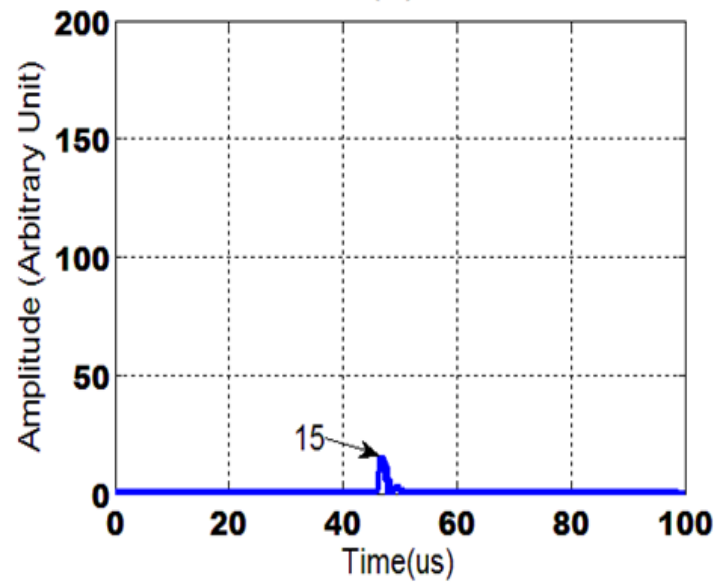

Fig. 11. The full-wave rectifier signal of ultrasonic Rayleigh wave propagating over the rectangular lattice, D06h50a32b90; receiver at the normal position, $\theta_{r}=0^{\circ}$ : (a) Transmitter at $\theta_{i}=30^{\circ}$, (b) Transmitter at $\theta_{i}=60^{\circ}$. 
(a)

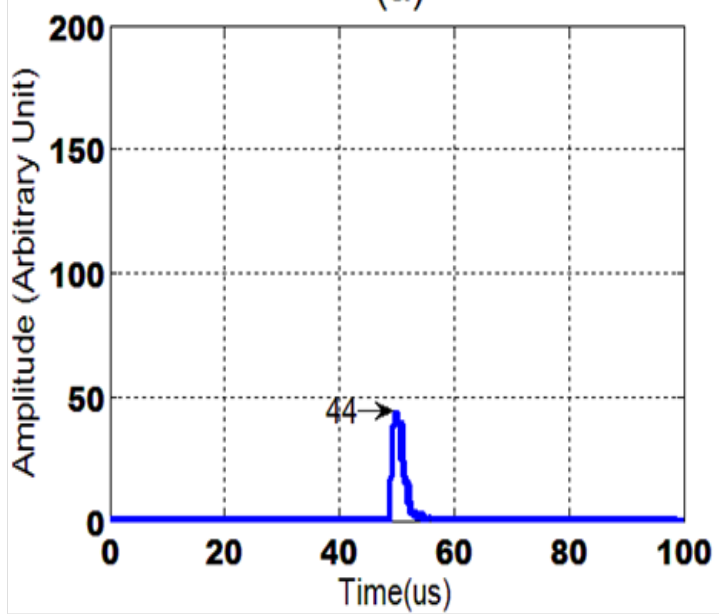

(b)

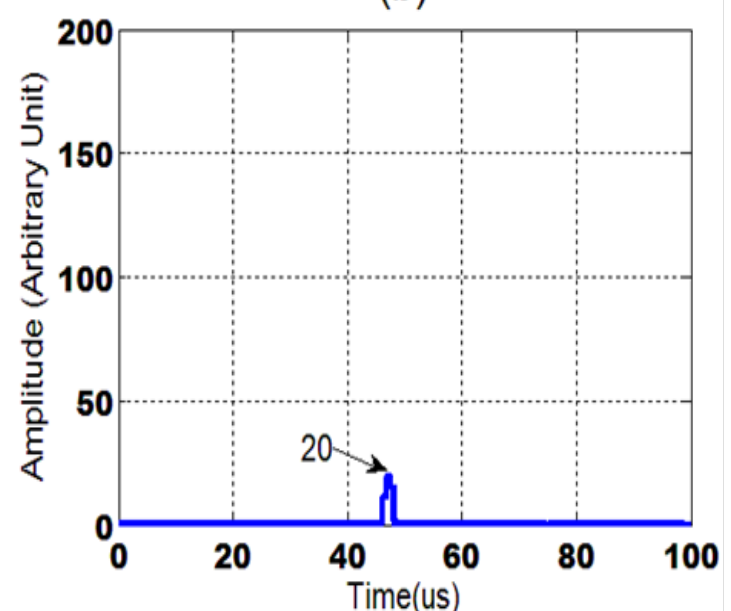

Fig. 12. The full-wave rectifier signal of ultrasonic Rayleigh wave propagating over the square lattice, D06h50a29; receiver at normal position, $\theta_{r}=0^{\circ}$ : (a) Transmitter at $\theta_{i}=30^{\circ}$, (b) Transmitter at $\theta_{i}=60^{\circ}$. 
(a)

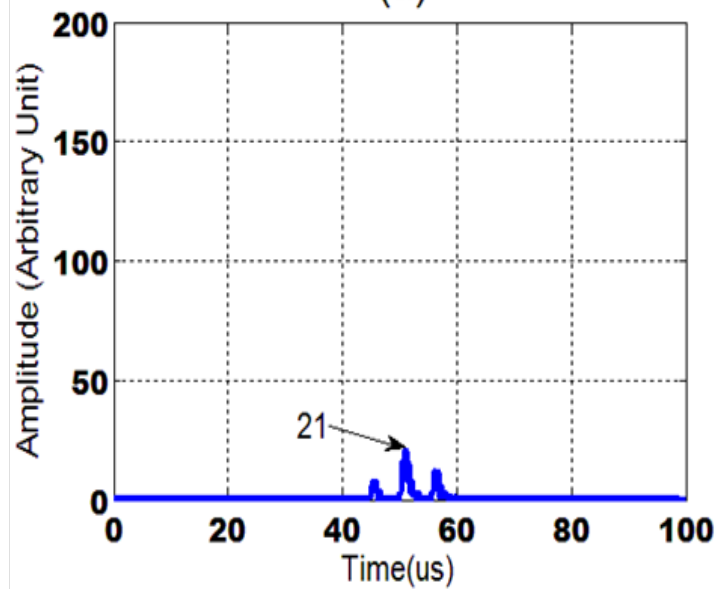

(b)

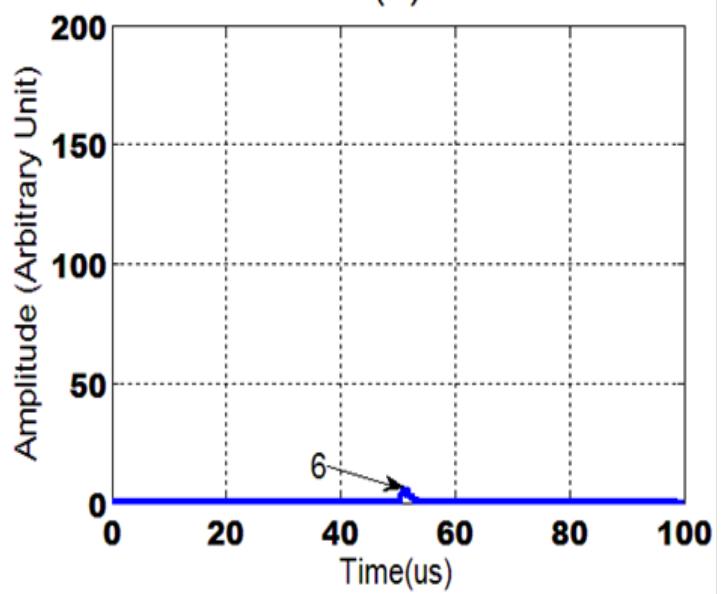

Fig. 13. Full-wave rectifier signal of ultrasonic Rayleigh wave reflection from the rectangular lattice D06h50a32b90: (a) $\theta_{i}=30^{\circ}, \theta_{r}=30^{\circ}$, (b) $\theta_{i}=60^{\circ}, \theta_{r}=$ $60^{\circ}$. 
(a)

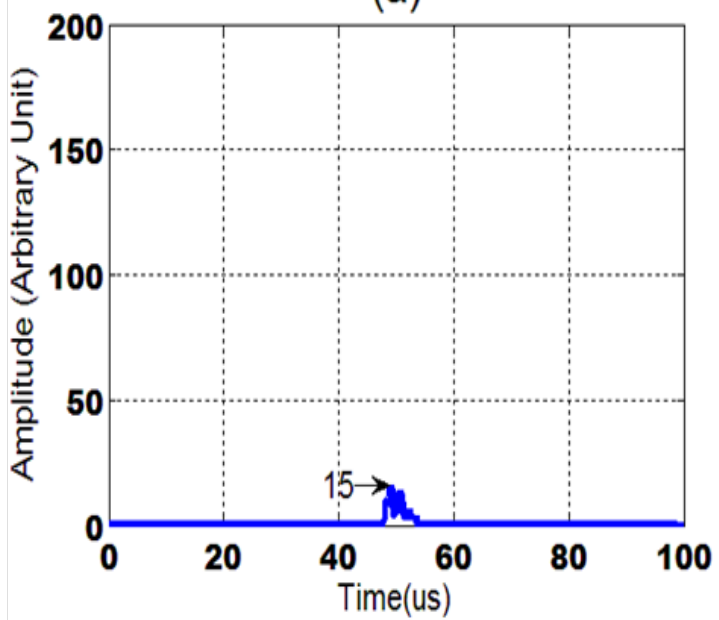

(b)

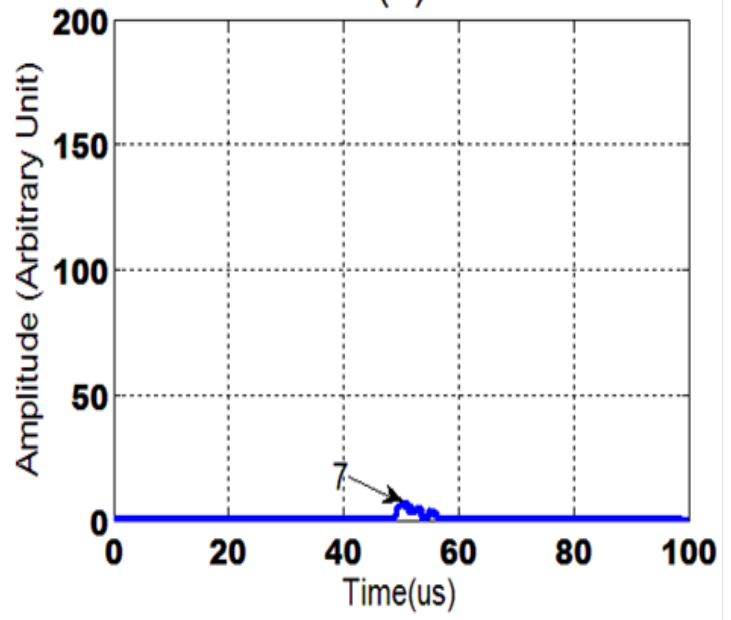

Fig. 14. Full-wave rectifier signal of ultrasonic Rayleigh wave reflection from square lattice, D06h50a29. (a) $\theta_{i}=30^{\circ}, \theta_{r}=30^{\circ}$, (b) $\theta_{i}=60^{\circ}, \theta_{r}=60^{\circ}$. 
(a)

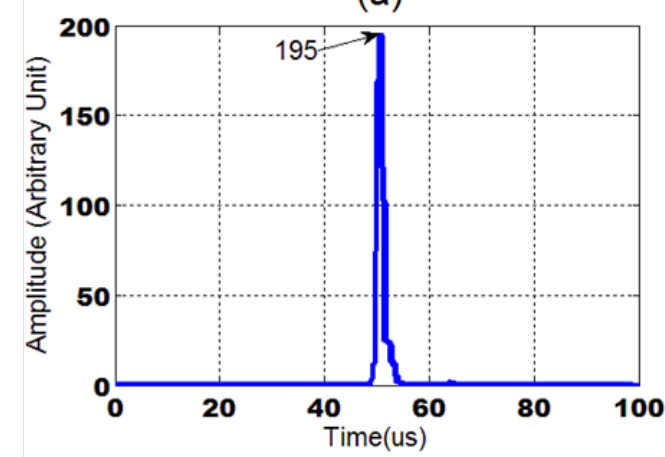

(c)

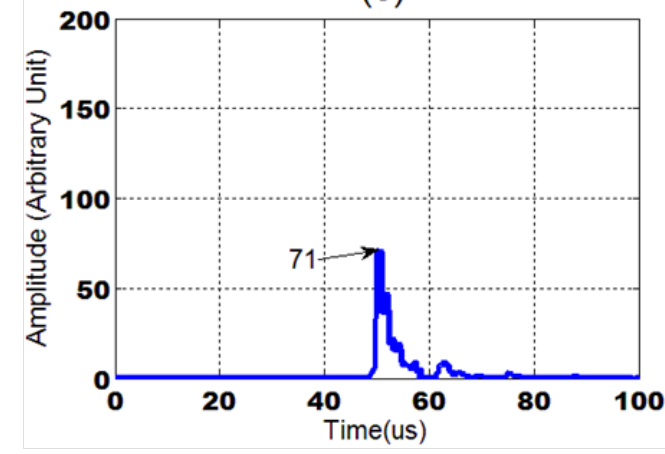

(b)

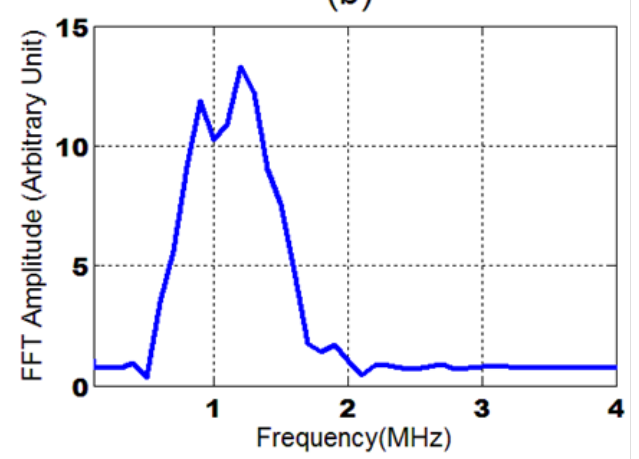

(d)

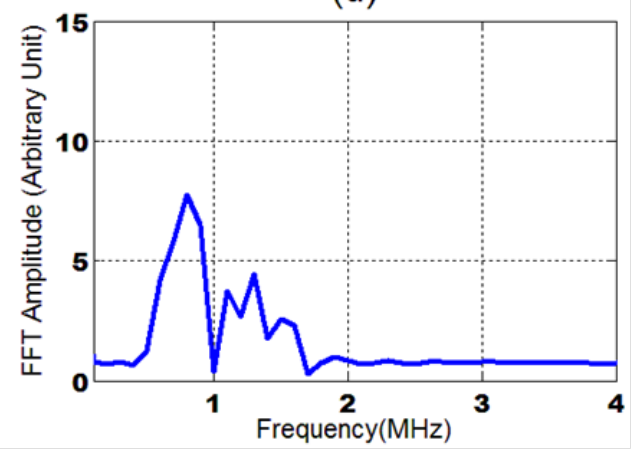

Fig. 15. Signals of ultrasonic Rayleigh waves, $\theta_{i}$ and $\theta_{r}=0^{\circ}$ : (a) Full wave rectifier signal transmitted over a smooth surface, (b) The corresponding frequency spectrum, (c) Full wave rectifier signal transmitted over a square lattice D12h92a32, and (d) The corresponding frequency spectrum. 
(a)

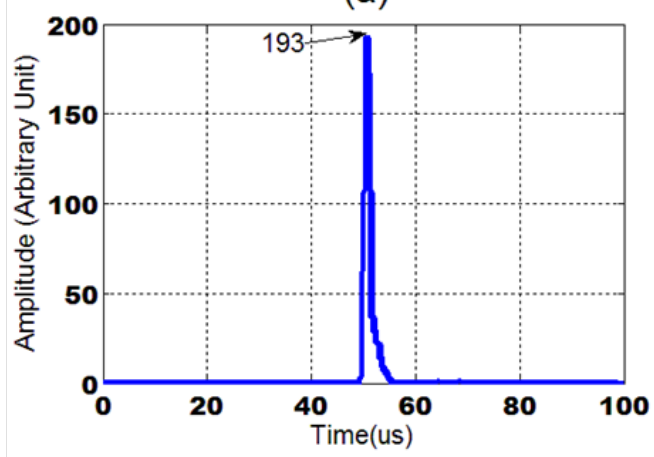

(c)

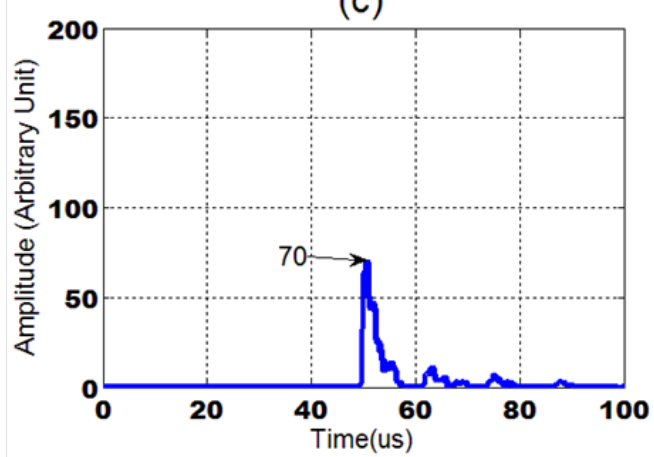

(b)

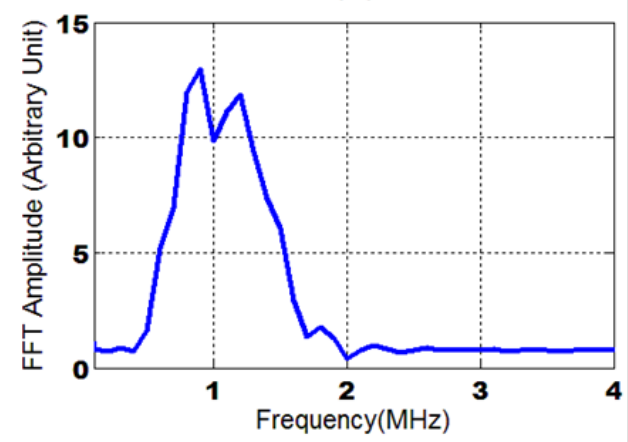

(d)

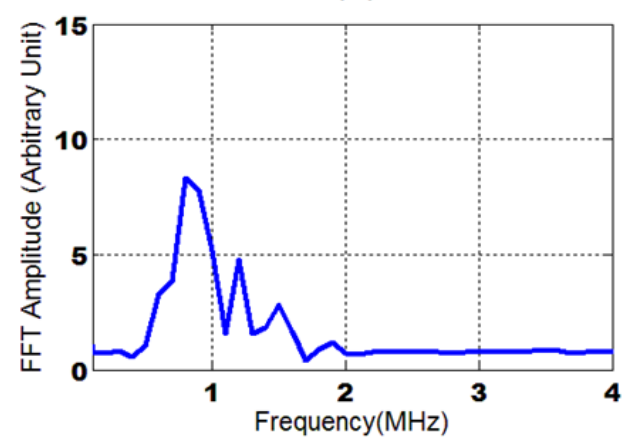

Fig. 16. Signals of ultrasonic Rayleigh waves, $\theta_{i}$ and $\theta_{r}=0^{\circ}$ : (a) Full wave rectifier signal transmitted over a smooth surface, (b) The corresponding frequency spectrum, (c) Full wave rectifier signal transmitted over a square lattice D12h92a29, and (d) The corresponding frequency spectrum. 
(a)

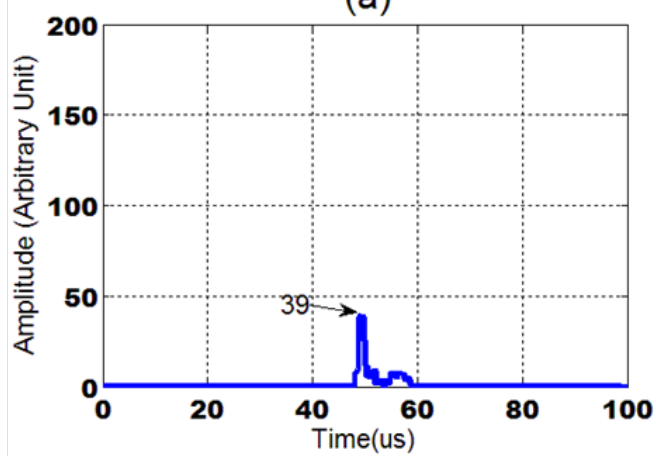

(b)

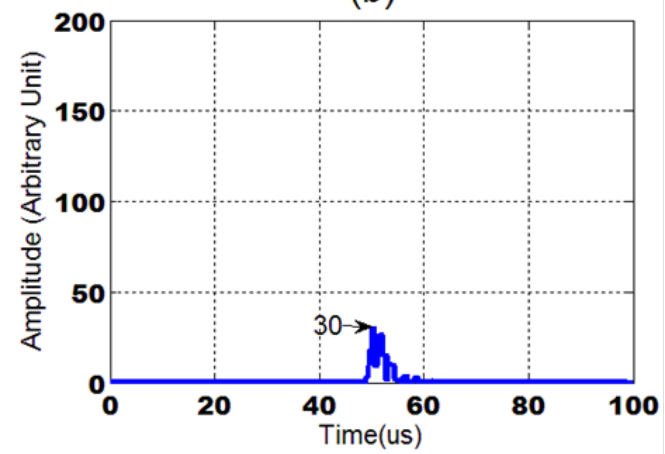

Fig. 17. Full-wave rectifier signal of ultrasonic Rayleigh wave reflection from the square lattice, D12h92a32: (a) $\theta_{i}=30^{\circ}, \theta_{r}=30^{\circ}$, (b) $\theta_{i}=60^{\circ}, \theta_{r}=60^{\circ}$. 
(a)

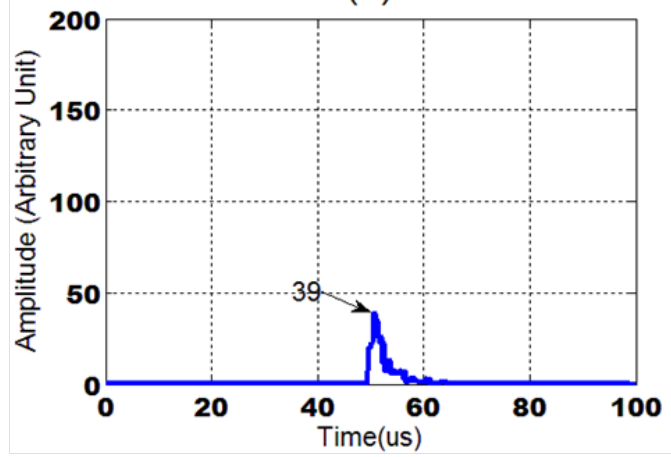

(b)

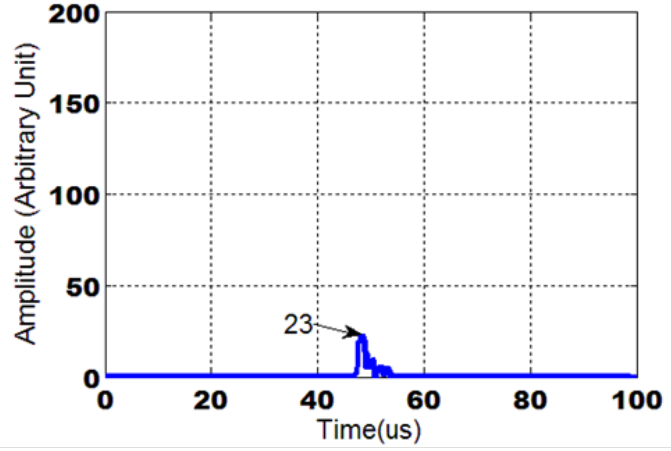

Fig. 18. Full-wave rectifier signal of ultrasonic Rayleigh wave reflection from the square lattice, D12h92a29: (a) $\theta_{i}=30^{\circ}, \theta_{r}=30^{\circ}$, (b) $\theta_{i}=60^{\circ}, \theta_{r}=60^{\circ}$. 